\title{
Retos de la contabilidad de gestión en el sector público.
}

Diego Alexander Quintanilla ${ }^{1}$

El desarrollo de los planes de gobiernos o planes de desarrollo como se suelen denominar en el contexto colombiano, exigen que la administración pública cuente con herramientas financieras y administrativas que permitan hacer un adecuado uso de los recursos públicos. Lo anterior implica que las Entidades públicas desarrollen cada uno de los proyectos basados en un trabajo multidisciplinario; el cual se ve plasmado en todas las fases del proyecto iniciando en el proceso de planeación, en donde se analizan las necesidades de la sociedad y las múltiples alternativas para generar un mayor bienestar social. Uno de los elementos que implica el análisis de alternativas o de intervención pública es el análisis de viabilidad financiera en donde se discriminan los recursos económicos que una entidad pública debe disponer para adelantar un proyecto.

En Colombia es difícil hablar del proceso de planeación del presupuesto público, lo anterior en razón a siempre se hace alusión que el presupuesto de las entidades públicas es limitado para las acciones que se requiere adelantar, por otra parte también es necesario mencionar que el manejo de los recursos públicos, en algunos casos, no responde a necesidades sociales sino a necesidades particulares; por lo tanto, ha sido cuestionado por los organismos de control y por la ciudadanía por los numerosos casos de corrupción en los cuales se ha visto el derroche de los recursos públicos, disminuyendo de esta

\footnotetext{
${ }^{1}$ Contador Público y Magister en Administración - Universidad Nacional de Colombia. Docente de la Facultad de Contaduría Pública de la Universidad Santo Tomás. Miembro del grupo de investigación Contaduría: Información, control e impacto social. E-mail: diegoquintanilla@usantotomas.edu.co
} 
manera la confianza y la legitimidad de las acciones de las entidades públicas. Esta situación del sector público en Colombia ha ocasionado, así como señala Gomez (2004), que se forjen más sistemas de control en donde el presupuesto público resulta ser más una camisa de fuerza dado que se enfatiza en el control del gasto en lugar de ser la cuantificación de los proyectos que se plasman desde los planes de desarrollo.

De tal forma que surge un reto en la Administración pública y es relacionado con articular los recursos públicos con los proyectos que pretende adelantar una entidad. Es aquí donde la contabilidad de gestión surge como un referente necesario para cumplir este propósito. La contabilidad de gestión entendida como un sistema de captación de información interna y externa para la medición, valoración y control de los recursos, que sirve como insumo para el proceso de toma de decisiones como la articulación de los planes estratégicos con los objetivos de la entidad. Apoya el proceso de planeación y de control de los recursos en los diferentes niveles organizacionales (estratégico, táctico y operativo).

Pérez M. (1999) identificó múltiples razones para implementar un sistema de contabilidad de gestión en las entidades públicas, entre las que se considera importante resaltar: i) Explicar la forma como se utilizan los recursos públicos desde la perspectiva de la eficiencia y la economía, ii) determinar las tasas y precios de los servicios públicos en caso de que se requiera aportes de los beneficiarios de estos servicios, ii) apoyar la elaboración y el análisis de presupuesto, cuando se realiza un análisis de costos sobre las diferentes alternativas para satisfacer una necesidad, lo cual fomenta la competencia en los procesos de selección de contratistas en las Entidades públicas, iii) reducir el riesgo de programas desfinanciados, lo cual posteriormente se traduce en mayores costos por parte de las entidades contratantes y v) facilitar la 
elaboración de información dirigida a organismos nacionales o internacionales que se encuentren interesados en contribuir con el desarrollo de un proyecto.

A su vez, De Lara, y otros, (2009) destacan que la adecuada administración de costos en las administraciones públicas es un "instrumento gerencial" escencial para el control de los gastos públicos y desempeño de las administraciones. De Maria y Leal (2015) manifiestan que la implantación obligatoria de sistemas de costos en las entidades públicas, podrían proporcionar un mayor volumen de información respaldando un adecuado proceso de rendición de cuentas.

En diferentes procesos de investigación relacionan la importancia de incorporar elementos de la contabilidad de gestión en el sector público, como por ejemplo Bastidas B. \& Moreno F (2007), resaltan el papel del cuadro de mando integral como un modelo que contribuye con el posicionamiento estratégico de las organizaciones, mediante la articulación de sus objetivos, metas con todas las instancias de una organización. La implementación del cuadro de mando integral se debe realizar con el desarrollo de sistemas de control de gestión, que para el caso del sector público debe ir acorde con el cumplimiento normativo y el exceso de formalidades que caracteriza el sector público.

Es necesario precisar que son pocos los procesos de investigación en Colombia en donde se aborda el impacto de implementar herramientas de contabilidad de gestión en el sector público, por lo tanto, resulta pertinente realizar investigaciones que evidencien la aplicación de estas herramientas, teniendo en cuenta que entre los objetivos estratégicos de Colombia Compra 
Eficiente $^{2}$ generar mayor valor (prosperidad, bienestar, calidad de vida) por dinero (recursos públicos).

\section{Bibliografía}

Bastidas B., E. L., \& Moreno F., Z. (2007). El cuadro de mando integral en la gestión de las organizaciones del sector público. Caso: Universidad Centroccidental Lisandro Alvarado. Compendium, Universidad Centroccidental Lisandro Alvarado, 10(18), 5-20.

De Lara, H., De Oliveira, G., Clemente, A., Dos Santos, B., Espejo, M., \& Bernardes, V. (2009). Custos no setor público: a percepção dos controladores de recursos. Revista del Instituto Internacional de Costos. 5, 373- 399.

De Maria, C., \& Leal, J. (2015). Custos no Setor Público: Aplicação da Contabilidade de Custos nos Serviços Públicos de Saúde Municipais. XXII Congresso Brasileiro de Custos, (pág. 16). Porto de Galinhas.

Gomez R., C. A. (2004). El presupuesto público en la gestión eficiente de los municipios. INNOVAR, revista de ciencias administrativas y sociales(24), 105111.

Pérez M., R. (1999). la contabilidad de gestión en la administración local: los sistemas de prestación de los servicios públicos y su influencia en la determinación de sus costes y evaluación de resultados. Albacete: Universidad de Castilla la Mancha.

\footnotetext{
${ }^{2}$ De acuerdo con el Articulo 2 del Decreto 4170 de 2011 esta Entidad tiene por objetivo "desarrollar e impulsar políticas públicas y herramientas, orientadas a la organización y articulación, de los partícipes en los procesos de compras y contratación pública con el fin de lograr una mayor eficiencia, transparencia y optimización de los recursos del Estado."
} 